\title{
Association of leukocyte mitochondrial DNA content with glioma risk: evidence from a Chinese case-control study
}

\author{
Jie Zhang ${ }^{1 \dagger}$, Deyang $\mathrm{Li}^{2 \dagger}$, Falin Qu ${ }^{2}$, Yibing Chen ${ }^{2}$, Gang Li ${ }^{3}$, Hequn Jiang ${ }^{1}$, Xiaojun Huang ${ }^{2}$, Hushan Yang ${ }^{4}$
} and Jinliang Xing ${ }^{2^{*}}$

\begin{abstract}
Background: Increasing evidence suggests that alterations in mitochondrial DNA (mtDNA) content may be implicated in the tumorigenesis of several malignancies. However, the association between mtDNA content in peripheral blood lymphocytes (PBLs) and glioma risk has not been investigated.

Methods: Real-time PCR was used to examine the mtDNA content in PBLs of 414 glioma patients and 414 matched controls in a hospital-based case-control study. The association between mtDNA content and glioma risk was evaluated using an unconditional multivariate logistic regression model.

Results: We found that glioma patients exhibited a significantly higher median mtDNA content than healthy controls (0.99 vs. $0.71, P<0.001)$. Unconditional multivariate logistic regression analysis adjusting for age, gender, smoking status, and family cancer history showed that there was an S-shaped association between mtDNA content and glioma risk. Higher mtDNA content was significantly associated with an elevated risk of glioma. Compared with the first quartile, the odds ratio (95\% confidence interval) for subjects in the second, third, and fourth quartiles of mtDNA content were 0.90 (0.52-1.53), 3.38 (2.15-5.31), and 5.81 (3.74-9.03), respectively ( $P$ for nonlinearity $=0.009)$. Stratified analysis showed that the association between mtDNA content and glioma risk was not modulated by major host characteristics.
\end{abstract}

Conclusions: Our findings demonstrate for the first time that a higher mtDNA content in PBLs is associated with an elevated risk of glioma, which warrants further investigation in larger populations.

Keywords: Case-control study, Mitochondrial DNA content, Peripheral blood leukocyte, Real-time PCR, Glioma risk

\section{Background}

Glioma is the most common primary brain tumor in both adults and children [1]. It is histologically classified into four grades (grades I-IV) according to the World Health Organization (WHO) guidelines and about 70\% of glioma is malignant (grade III/IV). The key features of malignant glioma include local invasive growth and strong angiogenesis. Despite many advances in surgical and medical therapies in recent years, the clinical outcome of this disease is still dismal under the best

\footnotetext{
* Correspondence: xingjinliang@163.com

${ }^{\dagger}$ Equal contributors

${ }^{2}$ State Key Laboratory of Cancer Biology \& Experimental Teaching Center of Basic Medicine, Fourth Military Medical University, Xi'an 710032, China

Full list of author information is available at the end of the article
}

available treatment regimen. The median overall survival is $12 \sim 14$ months in glioblastoma patients and $2 \sim$ 5 years in anaplastic astrocytoma patients. Currently, brain-imaging technology such as magnetic resonance imaging has proven to be the most effective method of diagnosing glioma. However, the use of brain imaging is dramatically limited in early preventive screening of glioma due to its high cost and low sensitivity for early stage glioma. Although numerous genetic and molecular research projects have been focused on the development of glioma, the pathogenesis of glioma is still poorly understood. Hence, there is a pressing need to develop novel specific susceptible biomarkers for the prediction of glioma risk and early diagnosis.

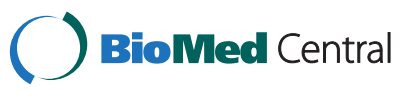


Mitochondria play pivotal roles in cellular energy production, free radical generation, apoptosis, and are the major intracellular source and primary target of reactive oxygen species (ROS) [2]. Human mitochondrial DNA (mtDNA) is a circular double-stranded DNA molecule with a length of $16569 \mathrm{bp}$. Each mitochondrion contains 2-10 mtDNA molecules. The copy number of mtDNA generally remains within a relatively stable range in order to maintain the cell's energy demands and preserve its normal physiological functions. However, mtDNA copy number may change from $10^{2}$ to $10^{4}$ per cell depending on the cell energy demands, and also vary in different cell types and tissue origins [3]. Compared with nuclear DNA, mtDNA lacks protective histones and appears to have less efficient repair mechanisms. Therefore, it is particularly susceptible to damage caused by ROS and other genotoxic agents [4]. Previous studies have indicated a potential involvement of both mtDNA mutations and alterations of mtDNA content (increased or decreased) in the tumorigenesis of many malignancies [5-8]. For example, mtDNA content in patient tissues has been found to be increased in cancers of head and neck, ovary and esophagus $[5,9,10]$, and decreased in hepatocellular carcinoma (HCC), advanced gastric cancer, osteosarcoma, breast cancer and renal cell carcinoma (RCC) [8,11-14]. In addition, several studies have demonstrated that the alterations of mtDNA content in peripheral blood lymphocytes (PBLs) can be used as a surrogate of constitutive genetic background to predict the risk of cancers such as RCC, breast cancer, lung cancer, non-Hodgkin lymphoma (NHL), and colorectal cancer (CRC) [15-19]. However, to date, the association between mtDNA content in PBLs and glioma susceptibility has not been determined.

In the present study, we conducted a case-control epidemiological analysis to examine the association between PBL mtDNA content and glioma risk. We measured the mtDNA content in PBLs from glioma patients and matched healthy controls using quantitative real-time PCR, and evaluated their associations with glioma risk using multivariate logistic regression model. To the best of our knowledge, this is the first epidemiological study to investigate the role of mtDNA content in glioma etiology.

\section{Methods}

\section{Study population}

In this case-control study, patients with histologically confirmed primary glioma were consecutively recruited from the Department of Neurosurgery in Tangdu Hospital affiliated with the Fourth Military Medical University, Xi'an, Shaanxi, China, between February 2010 and June 2012. Among a total of 495 eligible patients, 414 were successfully interviewed and donated biological specimens with a participation rate of $83.6 \%$ during the study period. All cases had no previous cancer history and no prior treatment at enrollment. There was no age, sex, or disease stage restriction for case recruitment. The 414 healthy controls without previous cancer history were recruited from individuals who visited the Tangdu Hospital for physical examination, during the same time period as the case enrollment. The response rate of controls was $73.2 \%$. The controls were frequency-matched to the cases on age ( \pm 3 years), sex and residential areas. All participants were Han Chinese.

\section{Epidemiological data}

After signed informed consent was obtained from each individual, all participants were interviewed by trained staff interviewers to collect demographic and personal data using a standardized epidemiological questionnaire, including age, gender, smoking history, family history of cancer, ionizing irradiation (IR) exposure history, and other potential confounders. Clinical information on pathological types was collected through pathological reports. Individuals who smoked less than 100 cigarettes during their lifetime were categorized as never-smokers. Individuals who smoked more than 100 cigarettes during their lifetime were categorized as ever-smokers. The number of pack-years was calculated as the average number of cigarettes smoked per day divided by 20 cigarettes and then multiplied by smoking years. All information exhibited high consistency except IR exposure history, which might stem from inaccurate understanding of IR exposure questionnaires. Therefore, data on IR exposure were not used for the further analyses in this study.

Before any treatment, $5 \mathrm{~mL}$ of venous blood from each participant was drawn into coded sodium citrate-coated tubes and centrifuged at $4^{\circ} \mathrm{C}$ under $1200 \times \mathrm{g}$ within 30 min. Genomic DNA was extracted from PBLs using the E.Z.N.A. Blood DNA Midi Kit (Omega Bio-Tek, Norcross, GA) and stored at $-80^{\circ} \mathrm{C}$ until PCR examination. Laboratory personnel were blinded to the casecontrol status of the samples. This study was approved by the Ethical Committee of the Fourth Military Medical University and performed in accordance with the ethical standards of the Helsinki Declaration.

\section{Determination of mtDNA content by quantitative real-time PCR}

Relative mtDNA content was measured by a quantitative real-time PCR-based method as previously described, with the same primers that were used for the mitochondrial ND1 gene (ND-R and ND-F) and the single-copy nuclear gene human globulin (HGB-1and HGB-2) [17]. In short, two pairs of primers were used in the two steps of relative quantification for mtDNA copy number. In the first step, the ratio of mtDNA copy number to HGB copy number was calculated for each sample from standard curves. In the second step, the ratio for each 
sample was normalized to a calibrator DNA in order to standardize between different runs, and then defined as the measurement of relative mtDNA content.

The PCR reaction system $(20 \mu \mathrm{L})$ consisted of $1 \times$ SYBR green mastermix (TaKaRa, Dalian, China), 10 nM ND1-R (or HGB-1) primer, $10 \mathrm{nM}$ ND1-F (or HGB-2) primer, and $8 \mathrm{ng}$ of genomic DNA. The thermal cycling conditions for both primer pairs were $95^{\circ} \mathrm{C}$ for $30 \mathrm{sec}$, followed by 35 cycles of $94^{\circ} \mathrm{C}$ for $30 \mathrm{sec}, 58^{\circ} \mathrm{C}$ for $30 \mathrm{sec}$, and $72^{\circ} \mathrm{C}$ for $50 \mathrm{sec}$ with signal acquisition. The PCRs were always performed on separate 96-well plates, with the same samples in the same well positions. All samples were assayed in duplicate using the Mx3005P QPCR System (Agilent, Santa Clara, CA). In each run, negative and positive controls, a calibrator DNA, and a standard curve were included. For each standard curve, one reference DNA sample (the same DNA sample for all runs) was diluted with a 3-fold increment per dilution to produce a 5-point standard curve between $0.593 \mathrm{ng}$ and $48 \mathrm{ng}$ DNA in each reaction. The $R^{2}$ for each standard curve was $\geq 0.99$, with acceptable standard deviations set at 0.25 (for the $\mathrm{Ct}$ values). Otherwise, the test was repeated.

\section{Statistical analysis}

All statistical analyses were performed using the SPSS Statistics 19.0 software (IBM). Normally distributed data were expressed as Mean \pm SD, while abnormally distributed data were expressed as median with a bracketed range. Pearson $x^{2}$ test was used to examine differences in the distribution of categorical variables including age, sex, smoking status, and family history of cancer among cases and controls. For the normally distributed continuous variables (pack-years of smoking), Student's $t$ test was used to test the differences between cases and controls. The significance of differences between cases and controls for abnormally distributed continuous variables (mtDNA content) was determined by Mann-Whitney U test. The mtDNA content was also analyzed as a categorical variable by grouping it based on the median, tertile or quartile values in the controls. The association between glioma risk and mtDNA content was estimated using odds ratio (OR) and 95\% confidential interval (CI) in unconditional multivariate logistic regression analysis after adjustment by age, sex, smoking status, and family history of cancer, where appropriate. A restricted cubic spline was plotted to evaluate the shape of the association as previously described [20]. Likelihood ratio tests were used to evaluate linear, effect, and overall effects of mtDNA content on glioma risk. All $P$ values reported were twosided, and $P<0.05$ was considered to be statistically significant.

\section{Results}

A total of 414 glioma patients and 414 matched healthy controls were included in this study. Table 1 summarized the characteristics of each type of distribution. The glioma cases and healthy controls were well-matched on sex $(P=1.00)$ and age $(P=0.491)$. There was no statistically significant difference between cases and controls in terms of family cancer history $(P=0.12)$, smoking status $(P=0.108)$, smoking pack-years $(P=0.342)$, platelet count $(P=0.110)$ white blood cell (WBC) count $(P=0.253)$ or the percentage of neutrophils $(P=0.144)$, lymphocytes $(P=0.116)$ or monocytes $(P=0.473)$ in WBC. Further analysis indicated that no significant correlation was found between mtDNA content and levels of platelet or white blood cell types (data not shown). These data suggest that levels of platelet or white blood cell types may not have notable effect on mtDNA content in blood samples. Among the total 414 cases, 175 patients were diagnosed with low-grade gliomas (WHO grade I/II) and 239 were diagnosed with high-grade gliomas (WHO grade III/IV).

We measured mtDNA content using a real-time PCRbased method in all samples. The mean inter-assay coefficient variation $(\mathrm{CV})$ of real-time PCR reaction was $6.9 \%$ (range, $3.9 \%$ to $9.1 \%$ ), whereas intra-assay CV was $4.2 \%$ (range, $2.4 \%$ to $6.9 \%$ ). We observed that mtDNA content in PBLs was significantly higher in glioma cases than that in controls $(P<0.001)$. The median values of normalized mtDNA content were 0.99 (range, 0.02-3.89) and 0.71 (range, 0.07-2.72) in cases and controls, respectively (Figure 1). Furthermore, we compared the mtDNA content according to host characteristics. As shown in Table 2, the case-control difference was still significant in all stratified subgroups. No significant modulating effect of selected characteristics on mtDNA content was found in both cases and controls, with $P$ value ranging from 0.101 to 0.982 .

We then performed an unconditional logistic regression analysis to evaluate the association between mtDNA content or other selected characteristics and glioma risk. When participants were dichotomized into high and low groups based on the median value of mtDNA content in controls (Figure 2), we observed that high mtDNA content was significantly associated with a 4.79-fold increase in risk of glioma (95\% CI, 3.49-6.59) in the univariate logistic regression model and a 4.82 -fold increase in risk of glioma $(95 \% \mathrm{CI}$, 3.50 - 6.63) after adjusting for the confounding effects of age, sex, smoking status and family history of cancer in the multivariate logistic regression model. Next, participants were categorized into three groups according to the tertile values of mtDNA content in healthy controls (Figure 2). When the first (lowest mtDNA content) tertile was used as the reference group, we observed that the adjusted ORs for the second and third tertile were 2.28 (95\% CI, 1.49 - 3.50) and 6.38 (95\% CI, 4.24 - 9.36), respectively. When participants were categorized into four groups according to quartile values of mtDNA content in healthy controls, the adjusted ORs for the second, third, and fourth quartiles 
Table 1 Distribution of selected characteristics in glioma cases and healthy controls

\begin{tabular}{|c|c|c|c|}
\hline Variables & Case $(n=414)$ & Control $(n=414)$ & $P$ value \\
\hline Age(years), No. (\%) & & & 0.491 \\
\hline$<47$ & $204(49.27)$ & $206(49.86)$ & \\
\hline$\geq 47$ & $210(50.73)$ & $208(50.14)$ & \\
\hline Sex, No. (\%) & & & 1.000 \\
\hline Male & $241(58.21)$ & $241(58.21)$ & \\
\hline Female & $173(41.79)$ & $173(41.79)$ & \\
\hline Smoking status, No. (\%) & & & 0.108 \\
\hline Never & $318(76.81)$ & 329 (79.47) & \\
\hline Ever & $96(23.19)$ & $85(20.53)$ & \\
\hline $\begin{array}{l}\text { Family history of } \\
\text { cancer, No. (\%) }\end{array}$ & & & 0.103 \\
\hline Yes & $45(10.87)$ & $32(7.73)$ & \\
\hline No & 369 (89.13) & $382(92.27)$ & \\
\hline $\begin{array}{l}\text { Pack-years of smoking }{ }^{a} \text {, } \\
\text { Mean (SD) }\end{array}$ & $26.20(14.94)$ & $25.29(13.05)$ & 0.342 \\
\hline $\begin{array}{l}\text { White blood cell count } \\
\left(10^{9} / \mathrm{L}\right) \text {, Mean (SD) }\end{array}$ & $6.2(4.17)$ & $5.9(3.32)$ & 0.253 \\
\hline $\begin{array}{l}\% \text { of neutrophils, Mean } \\
\text { (SD) }\end{array}$ & $64.7(25.32)$ & $62.2(23.85)$ & 0.144 \\
\hline $\begin{array}{l}\text { \% of lymphocytes, } \\
\text { Mean (SD) }\end{array}$ & $28.1(19.53)$ & $30.3(20.64)$ & 0.116 \\
\hline $\begin{array}{l}\% \text { of monocytes, Mean } \\
\text { (SD) }\end{array}$ & $5.4(3.88)$ & $5.6(3.35)$ & 0.473 \\
\hline $\begin{array}{l}\text { Platelet count }\left(10^{9} / \mathrm{L}\right) \text {, } \\
\text { Mean (SD) }\end{array}$ & $245(69.05)$ & $253(74.51)$ & 0.110 \\
\hline \multicolumn{4}{|l|}{ WHO grade } \\
\hline$|/| \mid$ & $175(42.27)$ & & \\
\hline III/IV & $239(57.73)$ & & \\
\hline
\end{tabular}

SD, standard deviation.

${ }^{\mathrm{a}}$ Only for ever smokers.

were 0.90 (95\% CI, 0.52 - 1.53), 3.38 (95\% CI, 2.15 - 5.31), and 5.81 (95\% CI, 3.74 - 9.03), respectively.

We further used a restricted cubic spline function in the logistic regression model to evaluate the shape of the association between mtDNA content and glioma risk. As shown in Figure 3, our result exhibited an S-shaped association between them. With the increase of mtDNA content, the glioma risk decreased before the inflection point $[\log ($ mtDNA content $)=-0.25]$; whereas glioma risk gradually increased with the increase of mtDNA content after the inflection point. The $P$ value of test for nonlinearity is 0.008 . Our stratified analysis showed that higher mtDNA content was associated with increased glioma risk in all strata (Table 3). We also analyzed the interactive effects of mtDNA content and host characteristics on the risk of glioma. The $P$ values for the interaction of mtDNA content with sex, age, smoking status and family cancer history were $0.193,0.467,0.072$ and

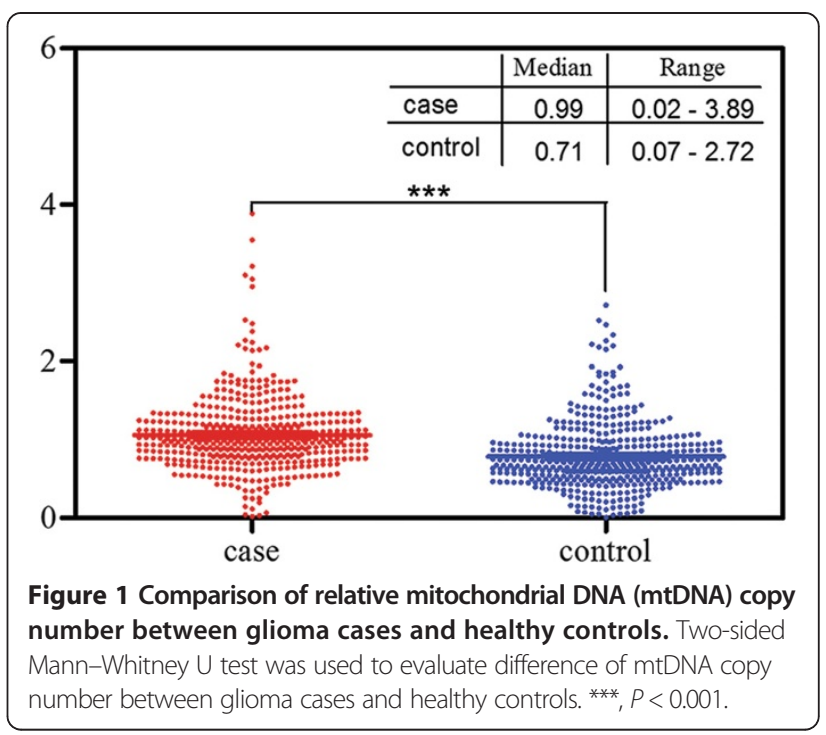

0.287 , respectively. These data suggest that the association between increased glioma risk and higher mtDNA content was not modulated by major host characteristics.

\section{Discussion}

In this case-control study, we found that glioma patients exhibited significantly higher mtDNA content than healthy controls. Our findings also demonstrated a typical S-shaped association between high mtDNA content and increased glioma risk. These results suggest that mtDNA content in PBLs might be a potential susceptibility biomarker for early preventive screening of glioma. To date, there are only a few risk factors identified to be associated with the risk of glioma, which only account for a small part of glioma cases [21]. Therefore, if our data are confirmed, novel strategy based on leukocyte mtDNA content examination can be established and would help to improve the screening of individuals who would probably develop glioma.

Several previous studies reported that higher mtDNA content in PBLs was significantly associated with an increased risk of NHL, lung cancer, and breast cancer $[18,19,22]$. These results are consistent with our present finding, indicating for the first time a similar positive correlation between PBL mtDNA content and glioma risk. Moreover, significant increase in mtDNA content has been found in both malignant glioma cell lines and tissues, suggesting that mtDNA content alteration may be an early molecular event in the development and progression of glioma [23-25]. Previous studies have also yielded similar results in cancers of endometrium, head and neck, thyroid gland [26], ovary [9], large intestine $[27,28]$, and lung [27], where mtDNA content was significantly higher in tumor tissues as compared with the corresponding non-tumor adjacent tissues. However, on 
Table 2 mtDNA copy number by host characteristics of glioma cases and healthy controls

\begin{tabular}{|c|c|c|c|c|c|}
\hline \multirow[t]{2}{*}{ Variables } & \multicolumn{2}{|r|}{ Case } & \multicolumn{2}{|r|}{ Control } & \multirow[t]{2}{*}{$P$ value } \\
\hline & No. & mtDNA copy number, median (range) & No. & mtDNA copy number, median (range) & \\
\hline \multicolumn{6}{|l|}{ Sex } \\
\hline Male & 241 & $0.98(0.12$ to 3.89$)$ & 241 & 0.70 (0.07 to 2.72$)$ & $<0.001$ \\
\hline Female & 173 & 1.01 (0.02 to 3.22$)$ & 173 & 0.74 (0.15 to 2.52$)$ & $<0.001$ \\
\hline$P$ value & & 0.431 & & 0.101 & \\
\hline \multicolumn{6}{|l|}{ Age, years } \\
\hline$<47$ & 204 & $0.96(0.02$ to 3.89$)$ & 206 & 0.70 (0.13 to 2.72$)$ & $<0.001$ \\
\hline$\geq 47$ & 210 & $1.03(0.03$ to 3.55$)$ & 208 & $0.72(0.07$ to 2.52$)$ & $<0.001$ \\
\hline$P$ value & & 0.165 & & 0.877 & \\
\hline \multicolumn{6}{|c|}{ Smoking status } \\
\hline Never & 318 & $0.98(0.02$ to 3.61$)$ & 329 & 0.69 (0.07 to 2.72$)$ & $<0.001$ \\
\hline Ever & 96 & 1.02 (0.03 to3.89) & 85 & $0.71(0.12$ to 2.55$)$ & 0.001 \\
\hline$P$ value & & 0.251 & & 0.267 & \\
\hline \multicolumn{6}{|c|}{ Family history of cancer } \\
\hline Yes & 45 & $0.90(0.03$ to 3.26$)$ & 32 & $0.72(0.18$ to 2.66$)$ & 0.002 \\
\hline No & 369 & 0.99 (0.02 to 3.89$)$ & 382 & 0.69 (0.07 to 2.72$)$ & $<0.001$ \\
\hline$P$ value & & 0.151 & & 0.803 & \\
\hline \multicolumn{6}{|c|}{ WHO grade } \\
\hline |//1 & 175 & 0.98 (0.04 to 3.55$)$ & & & \\
\hline III/IV & 239 & $1.00(0.02$ to 3.89$)$ & & & \\
\hline$P$ value & & 0.982 & & & \\
\hline
\end{tabular}

mtDNA, mitochondrial DNA.

the contrary, previous studies have also reported negative correlations between mtDNA content and risk of cancers such as HCC [29] and RCC [17]. Furthermore, in comparison to paired normal tissue, a significant decrease in mtDNA content was reported in the tumor tissue of cancers including HCC [29], gastric carcinoma [11], breast cancer [13,30], and RCC. Therefore, it is most likely that the change in mtDNA content is not simply a function of enhanced cellular proliferation in neoplastic cells, but also has some degree of specificity for particular cancer type. The reason for the tumor-specific association between mtDNA content and cancer risk remains to be evaluated, although it is likely to be regulated by various genetic, molecular, and cellular determinants.

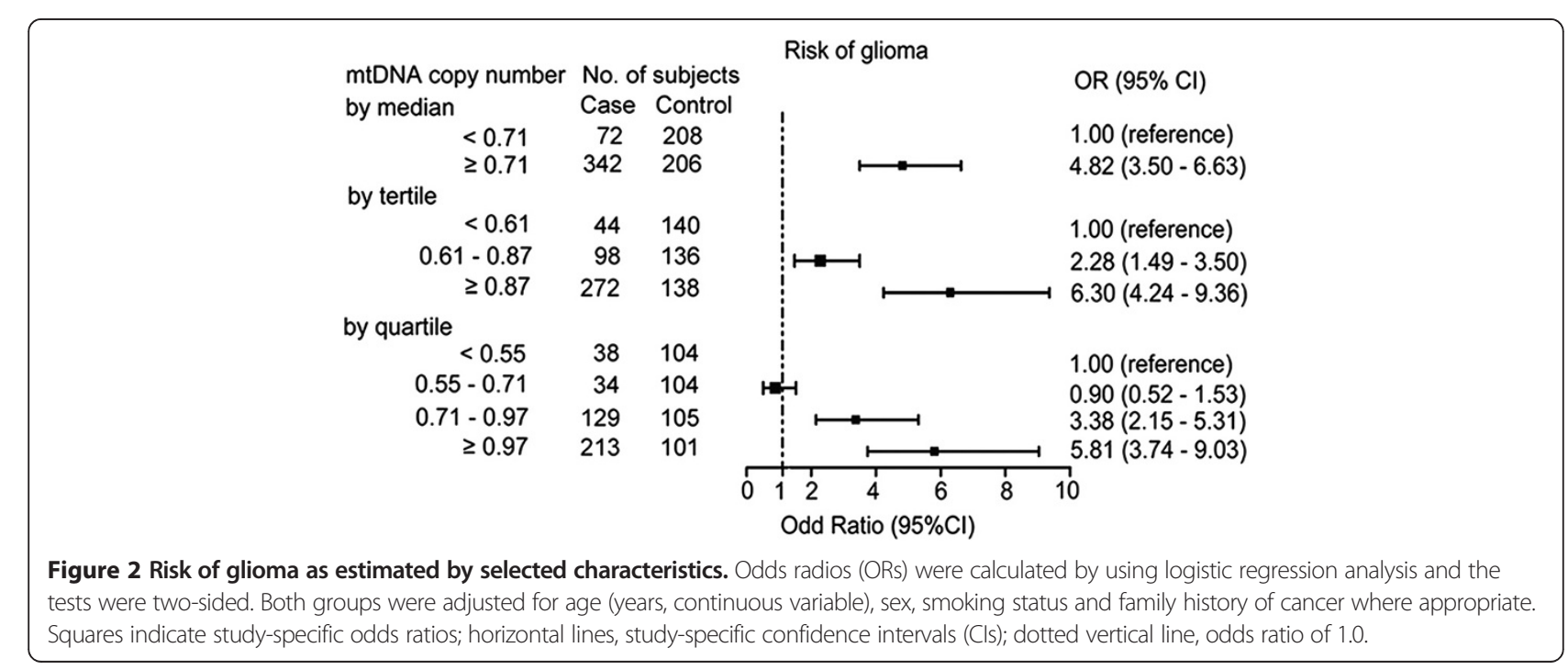




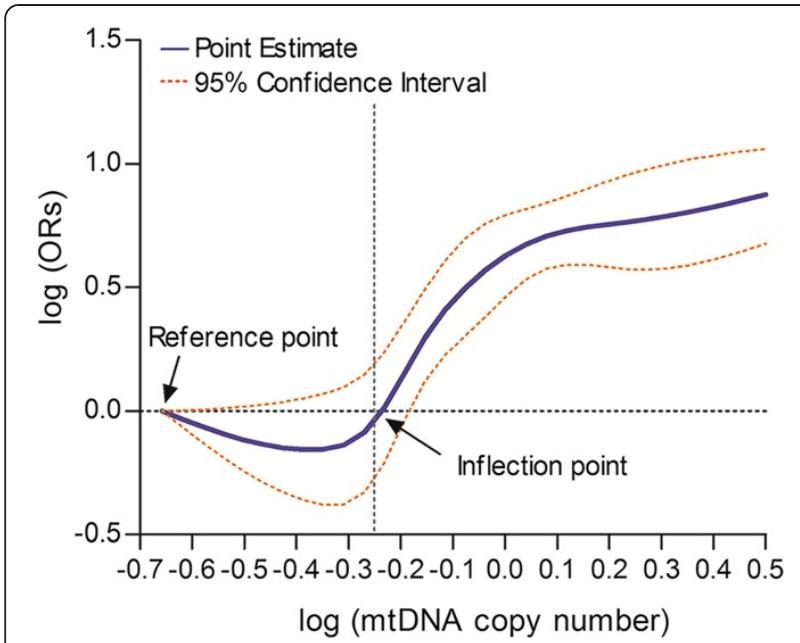

Figure 3 Association between leukocyte mitochondrial DNA (mtDNA) copy number and subsequent risk of glioma. mtDNA copy number and odds ratio (OR) values were transformed to common logarithm. There was an S-shaped relationship between mtDNA copy number and glioma risk ( $P$ for nonlinearity $=0.009$ ).

Further studies are needed to elucidate the molecular mechanisms underlying the association between mtDNA content and cancer risk.

In our study, we found that glioma cases exhibited higher leukocyte mtDNA content than healthy controls. However, this observational study could not tell whether mtDNA content alterations are the cause or consequence of tumorigenesis, which is a limitation inherent in casecontrol study design. A previous study have reported that mtDNA content appears to have high heritability (ie, proportion of phenotypic variation in a population that is attributable to genetic variation among individuals) [17]. In addition, several prospective studies have demonstrated that higher mtDNA content is associated with the risks of CRC [31], NHL [19], pancreatic cancer [32] and lung cancer [18]. In addition, our data also showed that glioma grade did not exhibit any remarkable effect on mtDNA content. All these findings suggest that alterations of mtDNA content may happen before cancer establishment. Future studies including animal cancer models and large prospective cohorts are needed to investigate the mtDNA content alterations and its biological roles in glioma.

Considering the crucial role of oxidative stress in tumorigenesis of glioma [25], our finding that higher mtDNA content was associated with an increased risk of glioma is not surprising. Elevated mtDNA content is commonly caused by some forms of oxidative stress in experimental models [33-35]. It has been shown that cells under mild oxidative stress may increase biogenesis of mitochondria and mtDNA through a pathway that bypasses cell-cycle control [36]. During the process of ROS-associated oxidative phosphorylation, accumulation of mtDNA mutations may occur [37]. Furthermore, mutated mtDNA may lead to aberrant mitochondrial biogenesis and then confer a replicative advantage to the cells [38]. Therefore, in our study, the case-control difference in mtDNA content might reflect the possible case-control difference in oxidative stress.

In the present study, we did not find any significant association between the mtDNA content and major host characteristics such as sex, age, smoking, and family history of cancer in both cases and controls. These observations are in line with some of the previous reports, but inconsistent with others that showed age- or smoking-

Table 3 mtDNA copy number and glioma risk estimates by selected variables

\begin{tabular}{|c|c|c|c|c|c|c|}
\hline \multirow[t]{2}{*}{ Variables } & \multicolumn{2}{|c|}{ Cases $^{a}(n)$} & \multicolumn{2}{|c|}{ Controls $^{\mathrm{a}}(\mathrm{n})$} & \multirow{2}{*}{$\begin{array}{l}\text { Adjusted } \mathrm{OR}^{\mathrm{b}} \\
(95 \% \mathrm{Cl})\end{array}$} & \multirow[t]{2}{*}{$P$ value } \\
\hline & High & Low & High & Low & & \\
\hline \multicolumn{7}{|l|}{ Sex } \\
\hline Male & 198 & 43 & 122 & 119 & 4.85 (3.52 to 6.71$)$ & $<0.001$ \\
\hline Female & 139 & 34 & 86 & 87 & 4.26 (2.83 to 5.94$)$ & $<0.001$ \\
\hline \multicolumn{7}{|l|}{ Age, years } \\
\hline$<47$ & 167 & 37 & 103 & 103 & 4.81 (3.42 to 6.69$)$ & $<0.001$ \\
\hline$\geq 47$ & 170 & 40 & 105 & 103 & 4.84 (3.59 to 6.65$)$ & $<0.001$ \\
\hline \multicolumn{7}{|c|}{ Smoking status } \\
\hline Never & 275 & 43 & 166 & 163 & 4.92 (3.43 to 6.82$)$ & $<0.001$ \\
\hline Ever & 62 & 34 & 42 & 43 & 1.98 (1.14 to 3.02$)$ & 0.014 \\
\hline \multicolumn{7}{|c|}{ Family history of cancer } \\
\hline Yes & 28 & 17 & 16 & 16 & 2.14 (1.19 to 3.36$)$ & 0.006 \\
\hline No & 309 & 60 & 192 & 190 & 4.89 (3.36 to 6.84$)$ & $<0.001$ \\
\hline
\end{tabular}

95\% Cl, 95\% confidence interval; mtDNA, mitochondrial DNA; OR, odds ratio.

${ }^{a}$ Cases and controls were dichotomized based on the median value of controls.

${ }^{\mathrm{b}}$ Adjusted by age, sex, smoking status, family history of cancer and histology type where appropriate. 
dependent changes in mtDNA content [39,40]. Additional larger studies with greater statistical power are needed to provide additional insights into the effects of interaction between mtDNA content and host variables on the modulation of glioma risk.

This study has several strengths and limitations. Our population is enrolled from Xi'an and its adjacent areas, which are highly attractive for conducting populationbased research. The geographical stability with low mobility rate could greatly reduce the potential confounding effects of the heterogeneous participant characteristics. However, because it was not a random sample of the general population, there was still a certain risk of selection bias if there were any difference in terms of the studied exposures. Moreover, due to inaccurate understanding of IR exposure questionnaire by participants, IR exposure data was not acceptably consistent when cross-check was performed by independent interviewers. We thus were unable to evaluate the mtDNA-IR interactions underlying risk of gliomas. Because the frequency of IR was rather low as reported by epidemiological studies in China [41], studies with larger sample size are still needed for a meaningful analysis on this interaction in future. In addition, our study cannot bypass the reverse-causation problem, an intrinsic limitation of the case-control study design, although previous studies have provided strong direct evidence that mtDNA content may serve as a constitutive genetic marker for cancer susceptibility. Therefore, future prospective epidemiological studies are warranted to further confirm our findings.

\section{Conclusions}

In summary, our data for the first time demonstrated that higher mtDNA content in PBLs was significantly associated with increased glioma risk. This is an initial step to evaluate whether the mtDNA content measured in PBLs can be used as a biomarker for early preventive screening of glioma. Once validated, mtDNA content could be incorporated with other available risk factors to construct a multivariate risk assessment model for identifying subjects with high risk of glioma.

\section{Competing interests}

The authors declare that they have no competing interests.

\section{Authors' contributions}

JX designed research and revised the final manuscript. JZ, DL and FQ performed research. YC and FQ analyzed data and wrote the paper. $\mathrm{HY}$ revised the final manuscript. JZ, GL, HJ and XH collected specimens. All authors read and approved the final manuscript.

\section{Acknowledgments}

This work was supported by Program for New Century Excellent Talents in University (to J.X.), National Natural Science Foundation (81171966 to J.X.), and National Key Technologies R\&D Program (2011ZX09307-001-04 to J.X.) of China.

\section{Author details}

'Department of Oncology, the First affiliated Hospital of Chengdu Medical College, Chengdu 610500, China. ${ }^{2}$ State Key Laboratory of Cancer Biology \& Experimental Teaching Center of Basic Medicine, Fourth Military Medical University, Xi'an 710032, China. ${ }^{3}$ Department of Neurosurgery, Tangdu Hospital, Fourth Military Medical University, Xi'an 710032, China. ${ }^{4}$ Division of Population Science, Department of Medical Oncology, Kimmel Cancer Center, Thomas Jefferson University, 19107 Philadelphia, PA, USA.

Received: 11 February 2014 Accepted: 17 September 2014 Published: 19 September 2014

\section{References}

1. Ostrom QT, Barnholtz-Sloan JS: Current state of our knowledge on brain tumor epidemiology. Curr Neurol Neurosci Rep 2011, 11(3):329-335.

2. Chan DC: Mitochondria: dynamic organelles in disease, aging, and development. Cell 2006, 125(7):1241-1252.

3. Veltri KL, Espiritu M, Singh G: Distinct genomic copy number in mitochondria of different mammalian organs. J Cell Physiol 1990 143(1):160-164.

4. Pinz KG, Bogenhagen DF: Efficient repair of abasic sites in DNA by mitochondrial enzymes. Mol Cell Biol 1998, 18(3):1257-1265.

5. Kim MM, Clinger JD, Masayesva BG, Ha PK, Zahurak ML, Westra WH, Califano JA: Mitochondrial DNA quantity increases with histopathologic grade in premalignant and malignant head and neck lesions. Clin Cancer Res 2004, 10(24):8512-8515.

6. Petros JA, Baumann AK, Ruiz-Pesini E, Amin MB, Sun CQ, Hall J, Lim S, Issa MM, Flanders WD, Hosseini SH, Marshall FF, Wallace DC: mtDNA mutations increase tumorigenicity in prostate cancer. Proc Natl Acad Sci U S A 2005, 102(3):719-724.

7. Wang Y, Liu WW, Xue WC, Tsang PC, Cheung AN, Ngan HY: The increase of mitochondrial DNA content in endometrial adenocarcinoma cells: a quantitative study using laser-captured microdissected tissues. Gynecol Oncol 2005, 98(1):104-110.

8. Lee HC, Li SH, Lin JC, Wu CC, Yeh DC, Wei YH: Somatic mutations in the D-loop and decrease in the copy number of mitochondrial DNA in human hepatocellular carcinoma. Mutat Res 2004, 547(1-2):71-78.

9. Wang Y, Liu WW, Xue WC, Cheung AN, Ngan HY: Association of decreased mitochondrial DNA content with ovarian cancer progression. Br J Cancer 2006, 95(8):1087-1091.

10. Lin CS, Chang SC, Wang LS, Chou TY, Hsu WH, Wu YC, Wei YH: The role of mitochondrial DNA alterations in esophageal squamous cell carcinomas. J Thorac Cardiovasc Surg 2010, 139(1):189-197. e184.

11. Wu CW, Yin PH, Hung WY, Li AF, Li SH, Chi CW, Wei YH, Lee HC: Mitochondrial DNA mutations and mitochondrial DNA depletion in gastric cancer. Genes Chromosomes Cancer 2005, 44(1):19-28.

12. Yu M, Wan Y, Zou Q: Reduced mitochondrial DNA copy number in Chinese patients with osteosarcoma. Transl Res 2013, 161(3):165-171.

13. Yu M, Zhou Y, Shi Y, Ning L, Yang Y, Wei X, Zhang N, Hao X, Niu R: Reduced mitochondrial DNA copy number is correlated with tumor progression and prognosis in Chinese breast cancer patients. IUBMB Life 2007, 59(7):450-457.

14. Meierhofer D, Mayr JA, Foetschl U, Berger A, Fink K, Schmeller N, Hacker GW, Hauser-Kronberger C, Kofler B, Sperl W: Decrease of mitochondrial DNA content and energy metabolism in renal cell carcinoma. Carcinogenesis 2004, 25(6):1005-1010.

15. Qu F, Liu X, Zhou F, Yang H, Bao G, He X, Xing J: Association between mitochondrial DNA content in leukocytes and colorectal cancer risk: a case-control analysis. Cancer 2011, 117(14):3148-3155.

16. Shen J, Platek M, Mahasneh A, Ambrosone CB, Zhao H: Mitochondrial copy number and risk of breast cancer: a pilot study. Mitochondrion 2010, 10(1):62-68

17. Xing J, Chen M, Wood CG, Lin J, Spitz MR, Ma J, Amos Cl, Shields PG, Benowitz NL, Gu J, de Andrade M, Swan GE, Wu X: Mitochondrial DNA content: its genetic heritability and association with renal cell carcinoma. J Natl Cancer Inst 2008, 100(15):1104-1112.

18. Hosgood HD 3rd, Liu CS, Rothman N, Weinstein SJ, Bonner MR, Shen M, Lim U, Virtamo J, Cheng WL, Albanes D, Lan Q: Mitochondrial DNA copy number and lung cancer risk in a prospective cohort study. Carcinogenesis 2010, 31(5):847-849. 
19. Lan Q, Lim U, Liu CS, Weinstein SJ, Chanock S, Bonner MR, Virtamo J, Albanes D, Rothman N: A prospective study of mitochondrial DNA copy number and risk of non-Hodgkin lymphoma. Blood 2008, 112(10):4247-4249.

20. Nunez E, Steyerberg EW, Nunez J: [Regression modeling strategies]. Rev Esp Cardiol 2011, 64(6):501-507.

21. Gu J, Liu Y, Kyritsis AP, Bondy ML: Molecular epidemiology of primary brain tumors. Neurotherapeutics 2009, 6(3):427-435.

22. Thyagarajan $B$, Wang $R$, Nelson $H$, Barcelo $H$, Koh WP, Yuan JM: Mitochondrial DNA copy number is associated with breast cancer risk. PloS One 2013, 8(6):e65968.

23. Liang BC: Evidence for association of mitochondrial DNA sequence amplification and nuclear localization in human low-grade gliomas. Mutat Res 1996, 354(1):27-33.

24. Liang BC, Hays L: Mitochondrial DNA copy number changes in human gliomas. Cancer Lett 1996, 105(2):167-173.

25. Zhang H, Kong $X$, Kang J, Su J, Li Y, Zhong J, Sun L: Oxidative stress induces parallel autophagy and mitochondria dysfunction in human glioma U251 cells. Toxicol Sci 2009, 110(2):376-388.

26. Mambo E, Chatterjee A, Xing M, Tallini G, Haugen BR, Yeung SC, Sukumar S, Sidransky D: Tumor-specific changes in mtDNA content in human cancer. Int J Cancer 2005, 116(6):920-924.

27. Lee HC, Yin PH, Lin JC, Wu CC, Chen CY, Wu CW, Chi CW, Tam TN, Wei YH: Mitochondrial genome instability and mtDNA depletion in human cancers. Ann N Y Acad Sci 2005, 1042:109-122.

28. Lin PC, Lin JK, Yang SH, Wang HS, Li AF, Chang SC: Expression of beta-F1ATPase and mitochondrial transcription factor $A$ and the change in mitochondrial DNA content in colorectal cancer: clinical data analysis and evidence from an in vitro study. Int J Colorectal Dis 2008, 23(12):1223-1232

29. Zhao S, Yang Y, Liu J, Liu H, Ge N, Yang H, Zhang H, Xing J: Association of mitochondrial DNA content in peripheral blood leukocyte with hepatitis $B$ virus-related hepatocellular carcinoma in a Chinese Han population. Cancer Sci 2011, 102(8):1553-1558.

30. Fan AX, Radpour R, Haghighi MM, Kohler C, Xia P, Hahn S, Holzgreve W, Zhong $X Y$ : Mitochondrial DNA content in paired normal and cancerous breast tissue samples from patients with breast cancer. J Cancer Res Clin Oncol 2009, 135(8):983-989.

31. Thyagarajan B, Wang R, Barcelo H, Koh WP, Yuan JM: Mitochondrial copy number is associated with colorectal cancer risk. Cancer Epidemiol Biomarkers Prev 2012, 21(9):1574-1581.

32. Lynch SM, Weinstein SJ, Virtamo J, Lan Q, Liu CS, Cheng WL, Rothman N, Albanes D, Stolzenberg-Solomon RZ: Mitochondrial DNA copy number and pancreatic cancer in the alpha-tocopherol beta-carotene cancer prevention study. Cancer Prev Res (Phila) 2011, 4(11):1912-1919.

33. Gadaleta MN, Rainaldi G, Lezza AM, Milella F, Fracasso F, Cantatore P: Mitochondrial DNA copy number and mitochondrial DNA deletion in adult and senescent rats. Mutat Res 1992, 275(3-6):181-193.

34. Shen Z, Wu W, Hazen SL: Activated leukocytes oxidatively damage DNA, RNA, and the nucleotide pool through halide-dependent formation of hydroxyl radical. Biochemistry 2000, 39(18):5474-5482.

35. Liu CS, Tsai CS, Kuo CL, Chen HW, Lii CK, Ma YS, Wei YH: Oxidative stressrelated alteration of the copy number of mitochondrial DNA in human leukocytes. Free Radic Res 2003, 37(12):1307-1317.

36. Lee $\mathrm{HC}$, Yin PH, Lu CY, Chi CW, Wei YH: Increase of mitochondria and mitochondrial DNA in response to oxidative stress in human cells. Biochem J 2000, 348(Pt 2):425-432.

37. Fliss MS, Usadel H, Caballero OL, Wu L, Buta MR, Eleff SM, Jen J, Sidransky D: Facile detection of mitochondrial DNA mutations in tumors and bodily fluids. Science 2000, 287(5460):2017-2019.

38. Carew JS, Nawrocki ST, Xu RH, Dunner K, McConkey DJ, Wierda WG, Keating MJ, Huang P: Increased mitochondrial biogenesis in primary leukemia cells: the role of endogenous nitric oxide and impact on sensitivity to fludarabine. Leukemia 2004, 18(12):1934-1940.

39. Lee HC, Lu CY, Fahn HJ, Wei YH: Aging- and smoking-associated alteration in the relative content of mitochondrial DNA in human lung. FEBS Lett 1998, 441(2):292-296.
40. Masayesva BG, Mambo E, Taylor RJ, Goloubeva OG, Zhou S, Cohen Y, Minhas K, Koch W, Sciubba J, Alberg AJ, Sidransky D, Califano J: Mitochondrial DNA content increase in response to cigarette smoking. Cancer Epidemiol Biomarkers Prev 2006, 15(1):19-24.

41. Zhou K, Liu Y, Zhang H, Liu H, Fan W, Zhong Y, Xu Z, Jin L, Wei Q, Huang F, Lu D, Zhou L: XRCC3 haplotypes and risk of gliomas in a Chinese population: a hospital-based case-control study. Int J Cancer 2009, 124(12):2948-2953.

doi:10.1186/1471-2407-14-680

Cite this article as: Zhang et al:: Association of leukocyte mitochondrial DNA content with glioma risk: evidence from a Chinese case-control study. BMC Cancer 2014 14:680.

\section{Submit your next manuscript to BioMed Central and take full advantage of:}

- Convenient online submission

- Thorough peer review

- No space constraints or color figure charges

- Immediate publication on acceptance

- Inclusion in PubMed, CAS, Scopus and Google Scholar

- Research which is freely available for redistribution

Submit your manuscript at www.biomedcentral.com/submit
C) BioMed Central 